\title{
Flux-density Harmonics Analysis of Switched-flux Permanent Magnet Machines
}

\author{
Zhiqiang Zeng ${ }^{1}$, Yiming Shen ${ }^{1}$, Qinfen $\mathrm{Lu}^{1}$, David Gerada ${ }^{2}$, Bocheng Wu${ }^{1}$, Xiaoyan Huang ${ }^{1}$, and Chris Gerada ${ }^{2}$ \\ ${ }^{1}$ College of Electrical Engineering, Zhejiang University, Hangzhou 310027, China \\ ${ }^{2}$ Department of Electrical and Electronic Engineering, University of Nottingham, Nottingham NG7 2RD, U.K.
}

\begin{abstract}
By developing a simple permeance-magnetomotive force (MMF) model of switched-flux permanent magnet (SFPM) machines, the air-gap flux-density produced by both permanent magnets (PM) and armature current can be derived, in which harmonics with the same order and rotational speed are called an effective-harmonic-pair (EHP). By investigating the influences of armature current angle $\delta$ on both the phase and amplitude of each EHP, it is found that the amplitudes of both PM and armature reaction flux-density harmonics maintain fixed, whereas the space phase shift between them changes accordingly with armature current angle. Specifically, the PM and armature reaction flux-density harmonics are orthogonal in space if zero $d$-axis current is fed. Therefore, the maximal torque is realized for each EHP. As the total torque of SFPM machines is the superposition of the contributions by each EHP, the zero $d$-axis current control method turns out to be the optimum for maximal torque per ampere, thus verifying analytically that the $d$ - and $q$-axis inductances are equal according to the general torque equation for the investigated machine topology. Besides, the torque adjustment mechanism of each EHP in SFPM machines has also been analytically demonstrated to be resemble that of surfacemounted PM synchronous machine (PMSM). Finally, finite-element analysis (FEA) has been performed to validate previous analytical predictions.
\end{abstract}

Index Terms - Effective-harmonic-pair, magnetic gearing effect, SFPM machine, torque adjustment mechanism.

\section{INTRODUCTION}

$\mathrm{S}$ WITCHED-FLUX PM (SFPM) machines have obtained increasing attention particularly in industrial applications, such as new energy automobiles and domestic appliances for the merits of high torque density, high efficiency, robust rotor, good thermal management, etc [1-4]. As newly-emergent stator-excited PM machines, their operating principles differ from those of the conventional PM synchronous machine (PMSM). As for the operation principle of SFPM machines, existing papers mainly focus on the flux-switching principle, viz. the periodic variation of induced phase Back-EMF due to rotor movement, typically addressed from a generator-oriented perspective [5]. Although this approach can be easyunderstanding to some extent, it cannot reveal the operating mechanism of SFPM machines in depth. In fact, identifying the torque production and adjusting principle analytically from a motor-oriented perspective, analyzing electrical machines through the interaction between armature reaction and excitation fields rather than open-circuit phase flux-linkages, gives more meaningful insight, which helps to reveal the nature of SFPM machines in further depth [6]. As known, equal pole-pair number as well as rotational speed of air-gap PM and armature reaction magnetic fields are essential to produce constant electromagnetic torque for any $\mathrm{PM} \mathrm{AC}$ machines, thus harmonic analysis of PM and armature reaction flux-densities is of great importance to reveal the torque production and adjustment principles of SFPM machines. Reference [7] has investigated the torque production mechanism of SFPM machines, showing that SFPM machines operate on multitudes of effective-harmonic-pairs (EHP) based on a magnetic gearing effect. However, it only deals with torque production mechanism and fails to investigate the torque adjustment mechanism of SFPM machines.
Armature $d$ - and $q$-axis inductances are generally assumed to be equal for SFPM machines, and thus zero $d$-axis current $i_{d}=0$ control method is often employed in order to maximize torque output under fixed armature current amplitude. However, the foregoing phenomenon is finite-element analysis (FEA) based and strict mathematical or analytical derivation has not been explored to date. Besides, it is difficult to figure out identical $d$ - and $q$-axis inductances for SFPM machines from perceptual intuition since they inherently exhibit doublesalient structures. In addition, to analytically investigate the torque adjustment principles as well as demonstrate equal $d$ and $q$-axis inductances of SFPM machines can provide powerful insights on the physical essence of such machines, which in return benefits both their optimization design and controls.

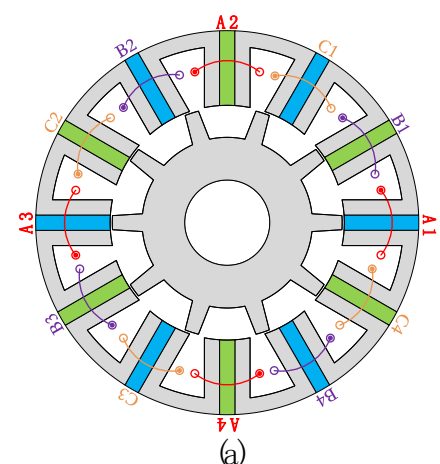

(a)

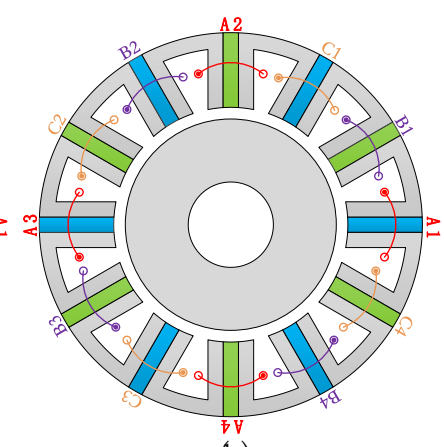

(b)
Fig. 1. Cross-sectional view of the three-phase 12s/10p SFPM machine. (a) Practical model. (b) Virtual model with smooth rotor.

The purpose of this paper is to analytically verify identical $d$ - and $q$-axis inductances for SFPM machines through air-gap flux-density harmonic analysis for different current angles $\delta$ from the motor-oriented perspective. This paper is organized as follows. In section II, the air-gap PM and armature reaction magnetomotive forces (MMFs) for arbitrary angle $\delta$ are 
derived based on a 12-stator-slot/10-rotor-pole (12s/10p) SFPM machine with a smooth rotor without considering rotor slotting effect. Then, PM and armature reaction flux-densities are obtained by multiplying the corresponding MMF and airgap permeance of a practical rotor model which takes rotor slotting into consideration. Furthermore, the impact of current angle $\delta$ on phase and amplitude of PM and armature reaction flux-density harmonics for all the EHPs is elaborately investigated in section III. After that, FEA is utilized to verify the claimed analytical results in Section IV. Finally, conclusions are drawn in section IV.

\section{MAGNETIC GEARING EFFECT OF SFPM MACHINES}

Fig. 1 shows the topology of a three-phase 12s/10p SFPM machine, on which the following mathematical inference of Fourier expressions of air-gap PM and armature reaction fluxdensities is based. This paper focuses on the analysis of harmonic components for PM and armature reaction fluxdensities and their relationship with the current angle $\delta$, which is defined as the armature current space vector preceding angle with respect to the $d$-axis in this paper. To show more clearly the physical essence of SFPM motors, magnetic saturation and leakage flux are not considered in the analytical derivations.

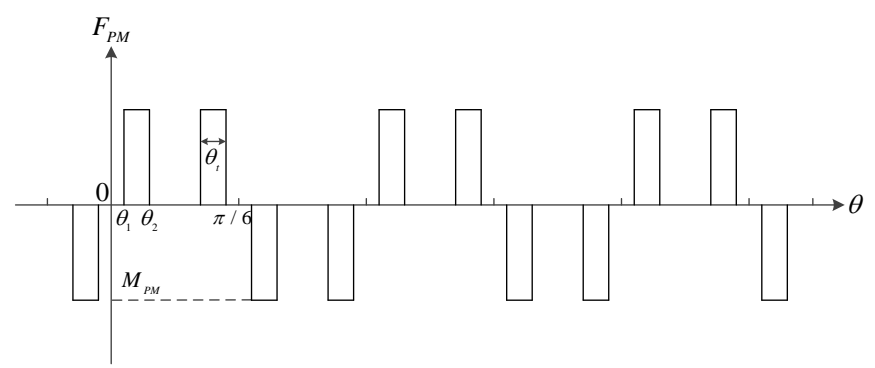

Fig. 2. Air-gap PM MMF waveform for virtual model with smooth rotor.

A. Fourier expressions of MMFs for the virtual model

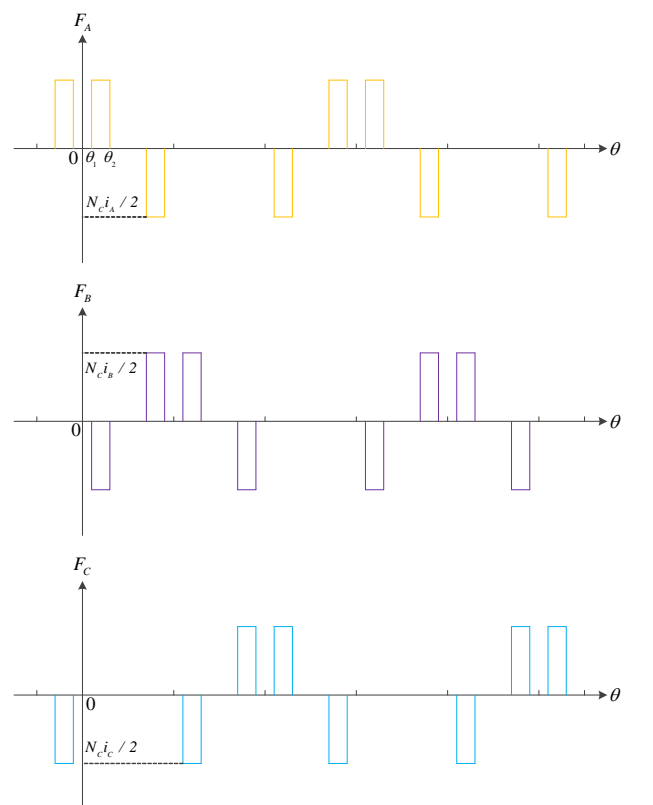

Fig. 3. Air-gap armature reaction MMF waveform for the virtual model.

Firstly, Fourier series of PM and armature reaction MMFs for the virtual model, shown in Fig.1(b), are derived under the aforementioned hypotheses. Letting the axis of Coil A1 to be the initial position, the PM MMF waveform can be got as shown in Fig. 2, where $\theta_{1}$ and $\theta_{t}$ represent half PM thickness and armature teeth width. The PM MMF waveform function, $F_{P M}(\theta)$ can be expressed as:

$$
\left\{\begin{array}{l}
\left.F_{P M}(\theta)=\sum_{i=1}^{\infty}\left\{M_{P M i} \sin \left[(2 i-1) P_{P M} \theta\right)\right]\right\} \\
M_{P M i}=\frac{4 M_{P M}}{\pi} \cdot \frac{\cos \left[(2 i-1) P_{P M} \theta_{1}\right]-\cos \left[(2 i-1) P_{P M} \theta_{2}\right]}{2 i-1}
\end{array}\right.
$$

where $M_{P M i}, P_{P M}, \theta$ are the amplitude of $(2 i-1)^{\text {th }}$ PM MMF harmonic, stator PM pole-pair number, and spatial circumferential mechanical angle respectively.

For the armature MMF, without consideration of rotor slotting, its waveform is shown in Fig. 3, with the corresponding Fourier series for each phase which can be expressed as:

$$
\begin{aligned}
& \left\{\begin{array}{l}
F_{A}(\theta, t)=F_{A 0}+N_{C} i_{A} \sum_{k=1}^{\infty} F_{k} \cos (4 k \theta) \\
F_{B}(\theta, t)=F_{B 0}+N_{C} i_{B} \sum_{k=1}^{\infty} F_{k} \cos [4 k(\theta-2 \pi / 3)] \\
F_{C}(\theta, t)=F_{C 0}+N_{C} i_{C} \sum_{k=1}^{\infty} F_{k} \cos [4 k(\theta+2 \pi / 3)]
\end{array}\right. \\
& F_{k}=\frac{1}{\pi k} \cdot\left\{\sin \left(4 k \theta_{2}\right)-\sin \left(4 k \theta_{1}\right)+\sin \left[4 k\left(\frac{\pi}{6}-\theta_{2}\right)\right]-\sin \left[4 k\left(\frac{\pi}{6}-\theta_{1}\right)\right]\right\}
\end{aligned}
$$

where $N_{C}, F_{k}$ are the number of turns per armature coil, and normalized armature MMF shape Fourier constant coefficient respectively. $i_{A}, i_{B}, i_{C}$ are the currents of phases $\mathrm{A}, \mathrm{B}, \mathrm{C}$, while $F_{A 0}, F_{B 0}, F_{C 0}$ represent the DC component of armature MMF for phases A, B, C respectively. Their sum is equal to zero since both three-phase currents and their spatial positions are symmetrical.

If initially the axis of phase A is aligned to the rotor $q$-axis position, the corresponding armature current space vector diagram can be represented as shown in Fig. 4. Therefore, the current equations can be expressed as:

$$
\left\{\begin{array}{l}
i_{A}=\sqrt{2} I \sin \left(N_{r} \Omega_{r} t+\delta\right) \\
i_{B}=\sqrt{2} I \sin \left(N_{r} \Omega_{r} t-2 \pi / 3+\delta\right) \\
i_{C}=\sqrt{2} I \sin \left(N_{r} \Omega_{r} t+2 \pi / 3+\delta\right)
\end{array}\right.
$$

where $\delta, I, N_{r}, \Omega_{r}$ represent the current angle and phase current RMS value, rotor pole number and rotational speed respectively. For motoring operation, $\delta$ should fulfill the condition of $\delta \in\left[0^{\circ}, 180^{\circ}\right]$.

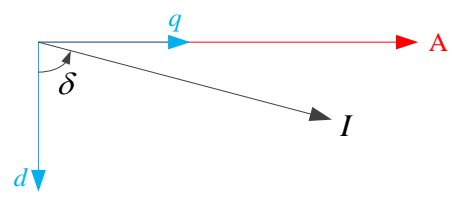

Fig. 4. Armature current space vector diagram at initial position. 
From equations (2) and (3), the synthesized three-phase armature MMF can be derived as:

$$
\left\{\begin{array}{c}
F_{A B C}(\theta, t)=\frac{3 \sqrt{2} I N_{C}}{2} \sum_{k=1}^{\infty}\left[F_{k} \sin (X)\right] \\
X= \begin{cases}N_{r} \Omega_{r} t+\delta+4 k \theta, & k=3 m-1 \\
N_{r} \Omega_{r} t+\delta-4 k \theta, & k=3 m-2 \\
0, & k=3 m\end{cases}
\end{array}\right.
$$

B. Air-gap flux-density harmonics for the practical rotor model

Fourier series $\mathrm{P}(\theta, t)$ of the air-gap permeance waveform of the practical motor model can be expressed as:

$$
\mathrm{P}(\theta, t)=P_{0}+\sum_{j=1}^{\infty}\left\{P_{j} \cos \left[\mathrm{j} N_{r}\left(\theta-\Omega_{r} t\right)\right]\right\}
$$

where $P_{0}, P_{j}$ represent the DC permeance and $j^{\text {th }}$ harmonic permanence amplitudes respectively.

Consequently, for the so-called practical model, the corresponding air-gap flux-density harmonics arising from PM and armature reaction MMFs can be derived by multiplying the corresponding MMF and air-gap permeance. As a result, the air-gap flux-density contributed by the PMs $B_{P M}(\theta, t)$ can be deduced by multiplying $F_{P M}(\theta)$ and $P(\theta, t)$ as follows:

$$
\begin{gathered}
\left.\mathrm{B}_{P M}(\theta, \mathrm{t})=P_{0} \sum_{i=1}^{\infty}\left\{M_{P M i} \sin \left[(2 i-1) P_{P M} \theta\right)\right]\right\}+ \\
\left.\sum_{j=1}^{\infty} \sum_{i=1}^{\infty}\left\{P_{j} \cos \left[j N_{r}\left(\theta-\Omega_{r} t\right)\right] M_{P M i} \sin \left[(2 i-1) P_{P M} \theta\right)\right]\right\} \\
\left.P_{j} \cos \left[j N_{r}\left(\theta-\Omega_{r} t\right)\right] M_{P M i} \sin \left[(2 i-1) P_{P M} \theta\right)\right]= \\
\frac{P_{j} M_{P M i}}{2}\left\{\begin{array}{l}
\sin \left[\left(j N_{r}+(2 i-1) P_{P M}\right) \theta-j N_{r} \Omega_{r} t\right]+ \\
\sin \left[\left(j N_{r}-(2 i-1) P_{P M}\right) \theta-j N_{r} \Omega_{r} t+\pi\right]
\end{array}\right\}
\end{gathered}
$$

As can be deduced from (6) and (7), the rotating air-gap field harmonics are generated due to the modulating effect of harmonic permeance to PM MMF, while the modulation of DC permeance to PM MMF still generates static PM field harmonics with identical pole-pair number and rotational speed to the source PM MMF. More specifically, modulation of DC permeance to $(2 \mathrm{i}-1)^{\text {th }}$ PM MMF harmonic produces a flux-density harmonic with a pole-pair number $(2 \mathrm{i}-1) P_{P M}$. In contrast, modulation of $j^{\text {th }}$ permeance harmonic to $(2 \mathrm{i}-1)^{\text {th }}$ PM MMF harmonic produces a flux-density harmonic with pole-pair number of $\left|j N_{r} \pm(2 i-1) P_{P M}\right|$. Characteristics of PM flux-density harmonics are listed in Table I.

$$
\text { TABLE I }
$$

AIR-GAP FLUX-DENSITY HARMONICS ARISING FROM PMS

\begin{tabular}{ccc}
\hline \hline Causes & Pole-pair number & Rotational speed \\
\hline $0 \rightarrow(2 \mathrm{i}-1)$ & $(2 \mathrm{i}-1) P_{P M}$ & 0 \\
\hline $\mathrm{j} \rightarrow(2 \mathrm{i}-1)$ & $j N_{r}+(2 i-1) P_{P M}$ & $\frac{j N_{r} \Omega_{r}}{j N_{r}+(2 i-1) P_{P M}}$ \\
\hline $\mathrm{j} \rightarrow(2 \mathrm{i}-1)$ & $\left|j N_{r}-(2 i-1) P_{P M}\right|$ & $\frac{j N_{r} \Omega_{r}}{j N_{r}-(2 i-1) P_{P M}}$ \\
\hline \hline
\end{tabular}

$\mathrm{A} \rightarrow \mathrm{B}$ indicating the modulation of $\mathrm{A}^{\text {th }}$ permeance harmonic to $\mathrm{B}^{\text {th }} \mathrm{PM}$ MMF harmonic.

Similarly, the airgap flux-density contributed by the armature current, $B_{A B C}(\theta, t)$ can be deduced by multiplying $F_{A B C}(\theta, t)$ and $P(\theta, t)$ yielding:

$$
\begin{aligned}
& \left\{\begin{array}{l}
B_{A B C}(\theta, t)=\frac{3 \sqrt{2} I N_{C} P_{0}}{2} \sum_{k=1}^{\infty}\left[F_{k} \sin (X)\right]+ \\
\sum_{j=1}^{\infty} \sum_{k=1}^{\infty}\left\{\frac{3 \sqrt{2} I N_{C}}{2} P_{j} F_{k} \cos \left[j N_{r}\left(\theta-\Omega_{r} t\right)\right] \sin (X)\right\} \\
X= \begin{cases}N_{r} \Omega_{r} t+\delta+4 k \theta, & k=3 m-1 \\
N_{r} \Omega_{r} t+\delta-4 k \theta, & k=3 m-2\end{cases}
\end{array}\right. \\
& \left\{\begin{array}{l}
P_{j} F_{k} \cos \left[j N_{r}\left(\theta-\Omega_{r} t\right)\right] \sin (X)= \\
\frac{P_{j} F_{k}}{2}\left\{\sin \left[\left(j N_{r}+\operatorname{sign} 4 k\right) \theta-(j-1) N_{r} \Omega_{r} t+\delta\right]\right. \\
\left.+\sin \left[\left(j N_{r}-\operatorname{sign} 4 k\right) \theta-(j+1) N_{r} \Omega_{r} t-\delta+\pi\right]\right\} \\
\operatorname{sign}= \begin{cases}-1, & k=3 m-2 \\
1, & k=3 m-1\end{cases}
\end{array}\right.
\end{aligned}
$$

From the foregoing analysis, it is apparent that the modulation of DC permeance to armature reaction source MMF produces flux-density harmonics with identical polepair number and rotational speed to the armature reaction MMF harmonics. However, the modulation of fundamental air-gap permeance to armature reaction MMF produces static flux-density harmonics, as is shown in the third row of Table II and second row of Table III. Similar to the modulation of air-gap permeance to PM MMF, the modulation of DC permeance to the $k^{\text {th }}$ armature reaction MMF harmonic produces flux-density harmonic with pole-pair number of $4 k$. Modulation of the $j^{\text {th }}$ permeance harmonic to the $k^{\text {th }}$ armature reaction MMF harmonic produces flux-density harmonic with pole-pair number of $\left|j N_{r} \pm 4 k\right|$. Characteristics of armature reaction flux-density harmonics are listed in Tables II and III.

TABLE II

AIR-GAP FLUX-DENSITY HARMONICS ARISING FROM ARMATURE CURRENT, $k=3 m-1$

\begin{tabular}{ccc}
\hline \hline Causes & Pole-pair number & Rotational speed \\
\hline $0 \rightarrow \mathrm{k}$ & $4 \mathrm{k}$ & $-\frac{N_{r} \Omega_{r}}{4 k}$ \\
\hline $\mathrm{j} \rightarrow \mathrm{k}$ & $\left|j N_{r}-4 k\right|$ & $\frac{(j+1) N_{r} \Omega_{r}}{j N_{r}-4 k}$ \\
\hline $\mathrm{j} \rightarrow \mathrm{k}$ & $j N_{r}+4 k$ & $\frac{(j-1) N_{r} \Omega_{r}}{j N_{r}+4 k}$ \\
\hline \hline
\end{tabular}

$\mathrm{A} \rightarrow \mathrm{B}$ indicating the modulation of $\mathrm{A}^{\text {th }}$ permeance harmonic to $\mathrm{B}^{\text {th }} \mathrm{PM}$ MMF harmonic.

TABLE III

AIR-GAP FLUX-DENSITY HARMONICS ARISING FROM ARMATURE CURRENT, $k=3 m-2$

\begin{tabular}{ccc}
\hline \hline Causes & Pole-pair number & Rotational speed \\
\hline $0 \rightarrow \mathrm{k}$ & $4 \mathrm{k}$ & $\frac{N_{r} \Omega_{r}}{4 k}$ \\
\hline $\mathrm{j} \rightarrow \mathrm{k}$ & $\left|j N_{r}-4 k\right|$ & $\frac{(j-1) N_{r} \Omega_{r}}{j N_{r}-4 k}$ \\
\hline $\mathrm{j} \rightarrow \mathrm{k}$ & $j N_{r}+4 k$ & $\frac{(j+1) N_{r} \Omega_{r}}{j N_{r}+4 k}$ \\
\hline \hline
\end{tabular}

$\mathrm{A} \rightarrow \mathrm{B}$ indicating the modulation of $\mathrm{A}^{\text {th }}$ permeance harmonic to $\mathrm{B}^{\text {th }} \mathrm{PM}$ MMF harmonic.

From the above analysis, it is reasonable to conclude that the modulation of DC air-gap permeance to both PM and armature reaction MMFs does not change the pole-pair number and rotational speed of corresponding MMF. However, it is the modulation of air-gap permeance harmonics 
to PM and armature MMFs that produces a vast number of new flux-density harmonics with different pole-pair numbers and rotational speeds from its source MMF. Besides, the modulation of the $j^{\text {th }}$ harmonic air-gap permeance to MMF with pole-pair number of $n$ will produce flux-density harmonics with a pole-pair number of $\left|j N_{r} \pm n\right|$, and this magnetic gearing effect lies in heterodyning principles. In a word, after the modulation of air-gap permeance harmonics to the original PM and armature reaction MMFs, lots of new field harmonics are generated and both PM and armature reaction flux-density harmonics are synchronized to each other, resulting in effective torque production of SFPM machines.

\section{ANALYSIS OF THE EHP}

For each EHP, the PM magnetic field is relatively static with the corresponding armature magnetic field, so their phase difference can be illustrated by phase difference at the initial position. It is worth mentioning that positive phase difference means that the armature magnetic field precedes the corresponding PM magnetic field.

In particular, if $k=3 m-1, N_{r}+4 k=12 m+6=$ $(2 m+1) P_{P M}$, which means that the armature reaction fluxdensity harmonic produced by the modulation of fundamental airgap permeance to the $k^{\text {th }}$ armature MMF harmonic is synchronous to the PM flux-density harmonic produced by the modulation of the DC air-gap permeance to $(2 m+1)^{\text {th }}$ PM MMF harmonic. Besides, similar phenomenon can be observed for other EHPs. The characteristics of all the EHPs are listed in Table IV and V, which clearly show that each of the armature reaction flux-density harmonic has its corresponding synchronized PM flux-density harmonic and thus they can form an EHP.

Interestingly, the phase difference between armature reaction and PM flux-density harmonics in each EHP varies accordingly with $\delta$, which can be characterized as follows in detail. The variation of $\delta$ contributes to the change of phase difference in all EHPs. Specifically, phase difference turns to be $0^{\circ}$ or $\pm 180^{\circ}$ if $\delta$ is equal to to $0^{\circ}$ or $180^{\circ}$. In contrast, phase difference is $\pm 90^{\circ}$ if $\delta$ is equal to $90^{\circ}$. As is known, orthogonal PM and armature magnetic fields result in maximal electromagnetic torque of EHP if the amplitudes of both magnetic fields are maintained constant. In other words, if $\delta$ is $90^{\circ}$, equivalent of zero armature $d$-axis current, maximal torque happens for each EHP. In addition, the total torque of SFPM machines is the sum of the torques produced by each EHP. Thus, zero $d$-axis current under fixed armature current amplitude also contributes to the largest torque output of SFPM machines. For any AC PM machine, its electromagnetic torque can be expressed as follows:

$$
T=\frac{3}{2} p\left[\psi_{P M} i_{q}+\left(L_{d}-L_{q}\right) i_{d} i_{q}\right]
$$

where $p, \Psi_{P M}, L_{d}, L_{q}, i_{d}, i_{q}$ are PM pole-pair number, PM flux-linkage, $d$ - and $q$-axis inductances, $d$ - and $q$-axis currents, respectively. However, for the case of SFPM machines, $p$ should be the rotor pole number since the movement of a rotor pole pitch corresponds to an electrical period.

TABLE IV

EFFECTIVE-HARMONIC-PAIRS, $k=3 m-1, \in\left[0^{\circ}, 180^{\circ}\right]$

\begin{tabular}{|c|c|c|c|}
\hline \multicolumn{2}{|c|}{ Pole-pair number } & \multirow[b]{2}{*}{ Rotational speed } & \multirow{2}{*}{$\begin{array}{c}\text { Phase } \\
\text { difference }\end{array}$} \\
\hline $\begin{array}{c}\text { Armature } \\
\text { reaction }\end{array}$ & PM & & \\
\hline $\mathrm{N}_{r}+4 k$ & $(2 m+1) P_{P M}$ & 0 & $\delta$ \\
\hline $4 k$ & $\begin{array}{l}\mid N_{r}-(2 m \\
+1) P_{P M} \mid\end{array}$ & $-N_{r} \Omega_{r} / 4 k$ & $\delta-180^{\circ}$ \\
\hline$\left|\mathrm{jN}_{r}-4 k\right|$ & $\begin{array}{l}\mid(j+1) N_{r}-(2 m \\
+1) P_{P M} \mid\end{array}$ & $\begin{array}{l}(\mathrm{j}+1) N_{r} \Omega_{r} /\left(j N_{r}\right. \\
-4 k)\end{array}$ & $-\delta$ \\
\hline $\begin{array}{c}\mathrm{jN}_{r}+4 k, \mathrm{j} \neq \\
1\end{array}$ & $\begin{array}{l}(j-1) N_{r}+(2 m \\
+1) P_{P M}\end{array}$ & $\begin{array}{l}(\mathrm{j}-1) N_{r} \Omega_{r} /\left(j N_{r}\right. \\
+4 k)\end{array}$ & $\delta-180^{\circ}$ \\
\hline
\end{tabular}

TABLE V

EFFECTIVE-HARMONIC-PAIRS, $k=3 m-2, \in\left[0^{\circ}, 180^{\circ}\right]$

\begin{tabular}{cccc}
\hline \hline \multicolumn{2}{c}{ Pole-pair number } & Rotational speed & $\begin{array}{c}\text { Phase } \\
\text { difference }\end{array}$ \\
\hline $\begin{array}{c}\text { Armature } \\
\text { reaction }\end{array}$ & $\mathrm{PM}$ & 0 & $\delta$ \\
\hline$\left|\mathrm{N}_{r}-4 k\right|$ & $|2(m-1)-1| P_{P M}$ & $N_{r} \Omega_{r} / 4 k$ & $-\delta+180^{\circ}$ \\
\hline $4 k, m \neq 1$ & $\begin{array}{c}\mid N_{r}+[2(m-1) \\
-1] P_{P M} \mid\end{array}$ & $N_{r} \Omega_{r} / 4 k$ & $-\delta$ \\
\hline $4 k, m=1$ & $N_{r}-P_{P M}$ & $(\mathrm{j}-1) N_{r} \Omega_{r}$ & $\delta-180^{\circ}$ \\
\hline $\begin{array}{c}\mid \mathrm{jN} \\
\mathrm{m}, \mathrm{j} \neq 1\end{array}$ & $\begin{array}{c}\mid(j-1) N_{r} \\
-1] P_{P M} \mid\end{array}$ & $/\left(j N_{r}-4 k\right)$ & \\
\hline$\left|\mathrm{jN} \mathrm{N}_{r}-2 k\right|, \mathrm{m}=$ & $\begin{array}{c}\left|(j-1) N_{r}+P_{P M}\right| \\
1, \mathrm{j} \neq 1\end{array}$ & $\begin{array}{l}(\mathrm{j}-1) N_{r} \Omega_{r} \\
/\left(j N_{r}-2 k\right)\end{array}$ & $\delta$ \\
\hline $\begin{array}{c}(j+1) N_{r} \\
\mathrm{~N}_{r}+4 k, m \neq \\
1\end{array}$ & $\begin{array}{c}(\mathrm{j}+1) N_{r} \Omega_{r} \\
-[2(m-1)\end{array}$ & $-\delta+180^{\circ}$ \\
\hline $\mathrm{jN}_{r}+4 k, m=$ & $\left(j N_{r}+4 k\right)$ & \\
\hline \hline
\end{tabular}

From equation (10), if maximal torque under fixed armature current amplitude occurs at $i_{d}=0$, this signifies that $L_{d}=L_{q}$. That is to say, reluctance torque can be neglected for SFPM machines and $i_{d}=0$ is equivalent of maximal torque per ampere (MTPA) control. In other words, the torque adjustment mechanism of SFPM machines resembles that of surface-mounted PMSM. Thus the fact that for SFPM machines, $L_{d}=L_{q}$, which is not easily discernable from the machine's geometrical structure, has been proved theoretically through the analysis of EHPs for different $\delta$ without considering the effects of magnetic saturation.

$$
\text { TABLE VI }
$$

KEY PARAMETERS OF THE 12S/10P FSPM MACHINE

\begin{tabular}{ccc}
\hline \hline Item & Value & Unit \\
\hline Stator outer diameter & 90 & $\mathrm{~mm}$ \\
\hline Stator inner diameter & 55 & $\mathrm{~mm}$ \\
\hline Airgap length & 0.5 & $\mathrm{~mm}$ \\
\hline Rotor outer diameter & 54 & $\mathrm{~mm}$ \\
\hline Rotor inner diameter & 20 & $\mathrm{~mm}$ \\
\hline Stack length, $L_{e f}$ & 25 & $\mathrm{~mm}$ \\
\hline PM remanence & 1.2 & $\mathrm{~T}$ \\
\hline PM relative recoil permeability & 1.05 & - \\
\hline Rated armature current & 11 & $\mathrm{~A}$ \\
\hline Rated speed & 400 & $\mathrm{r} / \mathrm{min}$ \\
\hline \hline
\end{tabular}

\section{FEA VALIDATION}

To validate the aforementioned analytical predictions, FEA 
of a three-phase 12s/10p SFPM machine with infinite relative permeability for ferromagnetic materials is performed, with its key parameter listed in Table VI.

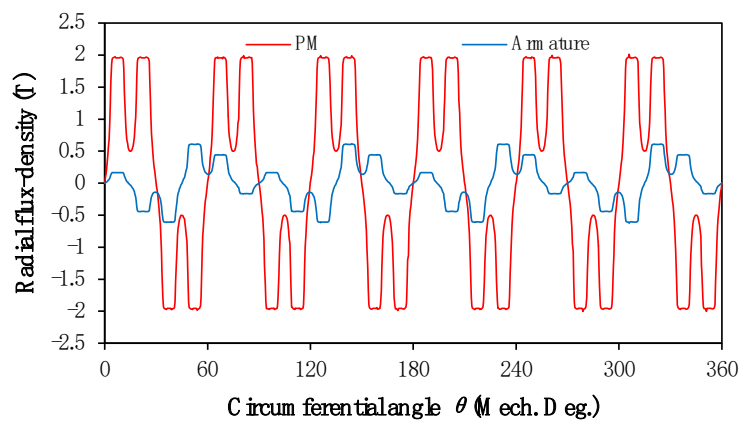

(a)

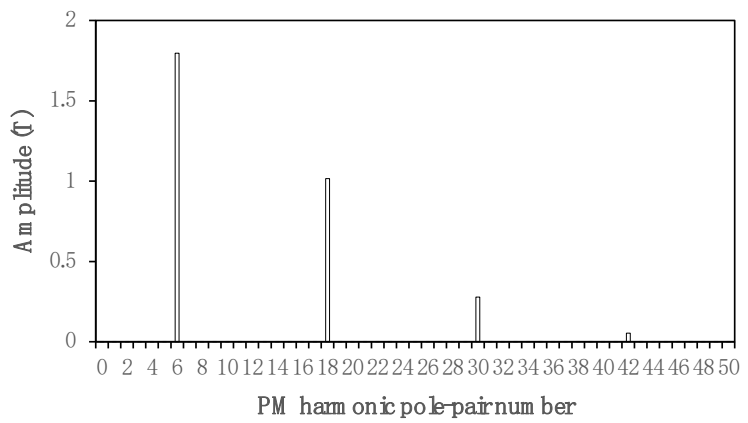

(b)

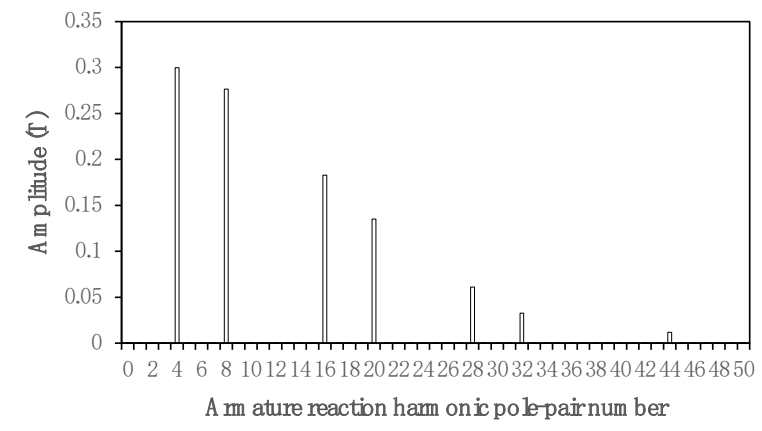

(c)

Fig. 5. Air-gap flux-density due to PMs and rated armature current without considering rotor slotting for the three-phase 12s/10p SFPM machine. (a) Flux-density waveforms. (b) Spectrum of PM flux-density. (c) Spectrum of armature reaction flux-density.

Firstly, air-gap magnetic fields of virtual model under only PM excitation and rated armature current $11 \mathrm{~A}$ are both shown in Fig. 5(a), and corresponding spectra are shown in Fig. 5(b) and Fig. 5(c), respectively. As is plotted in Fig. 5(b), pole-pair number of PM flux-density harmonics is $6,18,30$ and etc $\left((2 i-1) P_{P M}, i=1,2,3 \cdots\right)$, which is odd times of the polepair number of fundamental PM MMF and it well accords to the analytical predictions. For armature flux-density harmonics without rotor slotting, its spectrum is exhibited in Fig. 5(c). As it can be seen, pole-pair number of armature harmonics is $4,8,16,20,28$ and etc $(4 k, k \neq 3,6,9 \cdots)$, also agreeing well with previous analytical results. Moreover, it should be pointed out that the amplitude of each harmonic component decreases with the increase of harmonic order for both PM and armature reaction fields.
However, many other field harmonics are generated after the modulation of air-gap harmonic permeance to both PM and armature reaction MMFs. Fig. 6(a) shows the PM and armature reaction flux-density waveforms for practical model, which takes rotor slotting into consideration. Obviously, the flux-density waveforms are distorted seriously compared with that without consideration of rotor slotting in Fig. 5(a), indicating there are a vast number of harmonic components in the waveforms. Fig. 6(b) shows the spectrum of PM fluxdensity harmonics for practical model, apart from original harmonic components in Fig. 5(b), there are dominant new harmonics with pole-pair numbers of 4, 8, 16, $28\left(\mid N_{r} \pm(2 i-\right.$ 1) $\left.P_{P M} \mid, i=1,2\right)$. Similarly, there are also new dominant armature reaction field harmonics as shown in Fig. 6(c), and the main harmonics are 2, 6, 14, $18\left(\left|N_{r} \pm 4 k\right|, k=1,2\right)$. Therefore, it means that the main new field harmonics are caused by the modulation of fundamental permeance to the first and second order MMF harmonics.

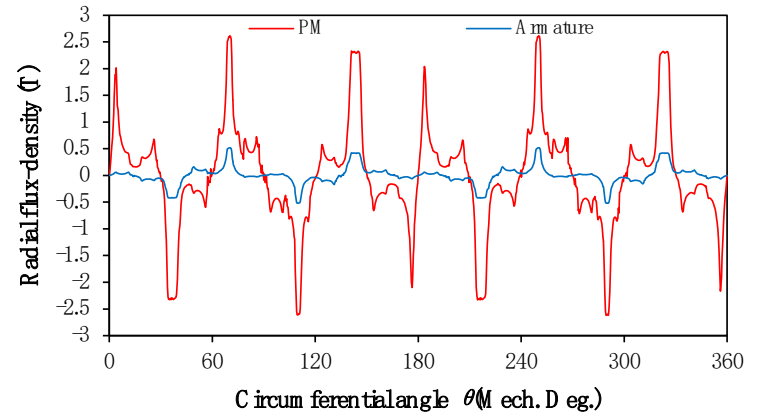

(a)

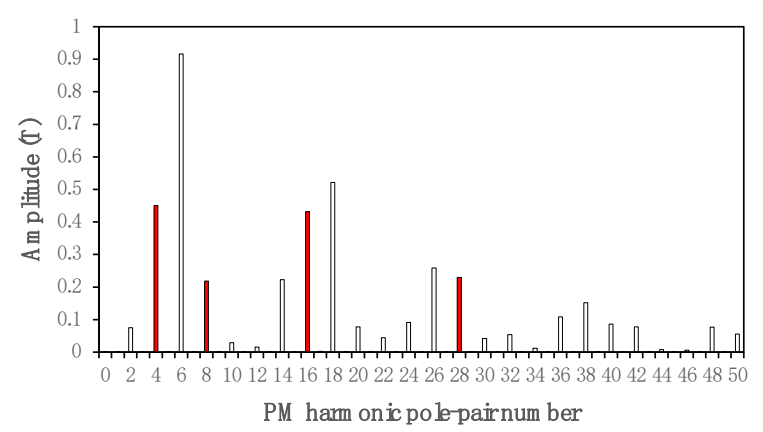

(b)

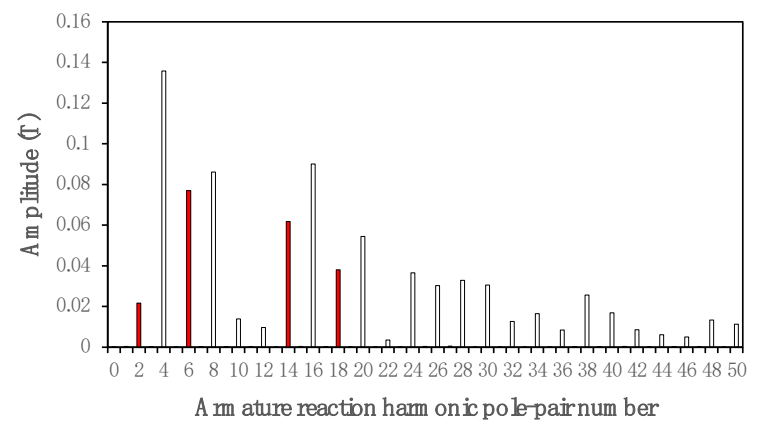

(c)

Fig. 6. Air-gap flux-density due to PMs and rated armature current for the three-phase 12s/10p SFPM machine. (a) Flux-density waveforms. (b) Spectrum of PM flux-density. (c) Spectrum of armature reaction flux-density. 
Based on the Maxwell Stress Tensor method, the effective torque $T_{n}$ contributed by field harmonics with pole-pair number $n$ can be expressed as the following equation

$$
T_{n}=\frac{\pi R^{2} L_{e f}}{\mu_{0}} B_{r_{-} n} B_{t_{-} n} \cos \varphi_{r t_{-} n}
$$

where $R, B_{r_{n} n}, B_{t \_n}, \varphi_{r t n}$ are the air-gap radius, amplitude of radial flux-density harmonic, amplitude of tangential fluxdensity harmonic, and phase difference between radial and tangential harmonics, respectively.

$$
\text { TABLE VII }
$$

TORQUE CONTRIBUTIONS OF AIR-GAP FIELD HARMONICS FOR THE

\begin{tabular}{|c|c|c|c|c|c|c|c|}
\hline \multirow{2}{*}{ Item } & \multicolumn{6}{|c|}{ Harmonic pole-pair number } & \multirow{2}{*}{ Total } \\
\cline { 2 - 7 } & 4 & 6 & 8 & 16 & 18 & 28 & \\
\hline $\begin{array}{c}\text { Torque } \\
\text { contribution } \\
(\%)\end{array}$ & 25.86 & 27.42 & -10.36 & 29.76 & 15.89 & 3.99 & 92.56 \\
\hline
\end{tabular}

Since air-gap PM and armature field harmonics are dominated by several harmonic orders as previously stated, the effective torque produced by other EHPs is minimal and thus can be almost neglected. In other words, most of the average torque is produced by several typical EHPs. To validate this claim, the average torque of the 12s/10p SFPM machine under rated $q$-axis current $15.56 \mathrm{~A}$ is calculated by using FEA, and the torque contributions of each EHP are also calculated by using equation (11), with the FEA-predicted results listed in Table VII. Clearly, the majority of the average torque is contributed by several field harmonics. Specifically, over $92 \%$ of the average torque is produced by harmonics with pole-pair numbers of $4,8,16,28\left(\left|N_{r} \pm(2 i-1) P_{P M}\right|, i=1,2\right)$ and 6 , $18\left((2 i-1) P_{P M}, i=1,2\right)$.

To further validate the aforementioned phase relationships between PM and armature reaction flux-density harmonics in each EHP, the phase variations of PM and armature fluxdensity harmonics with rotor position are plotted in Fig. 7. It should be mentioned that here four typical pole-pair numbers are extracted for a fair comparison since they are dominant in amplitude as can be seem from Fig. 6(b). As is shown, if $\delta=$ $0^{\circ}$, the phase differences between PM and armature fields in each EHP are exactly $0^{\circ}$ as can be seen from comparing Fig. 7(a) and Fig. 7(b). In contrast, phase differences approximate $\pm 90^{\circ}$ if $\delta=90^{\circ}$, which can be observed by comparing Fig. 7(a) and Fig. 7(c). Therefore, the FEA-predicted results are in good accordance with corresponding analytical predictions in Table IV and Table V.

Finally, the $d$ - and $q$-axis inductances of the 12s/10p SFPM machines are calculated by FEA. As is shown in Fig. 8, the $d$ axis and $q$-axis inductances agree well with each other in numerical value, with corresponding average values over an electrical period to be 389.22 and $390.62 \mu \mathrm{H}$, respectively.

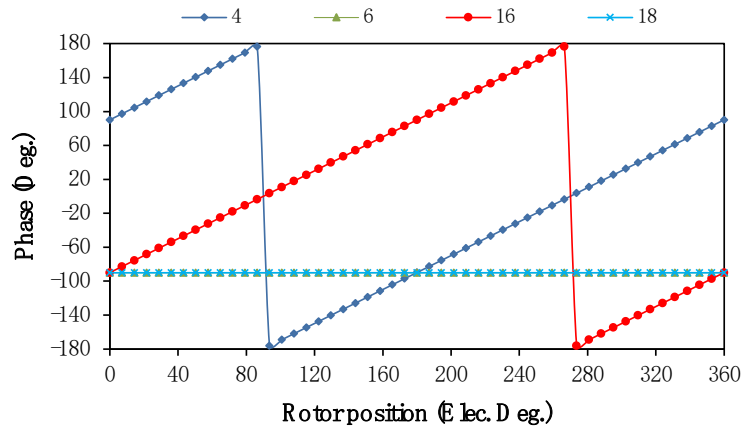

(a)

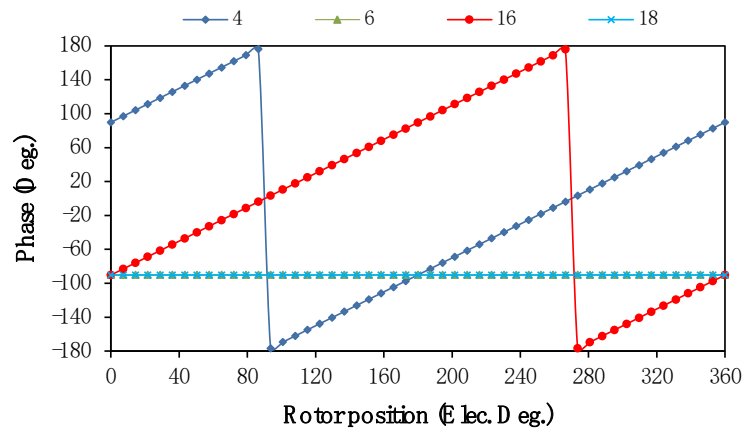

(b)

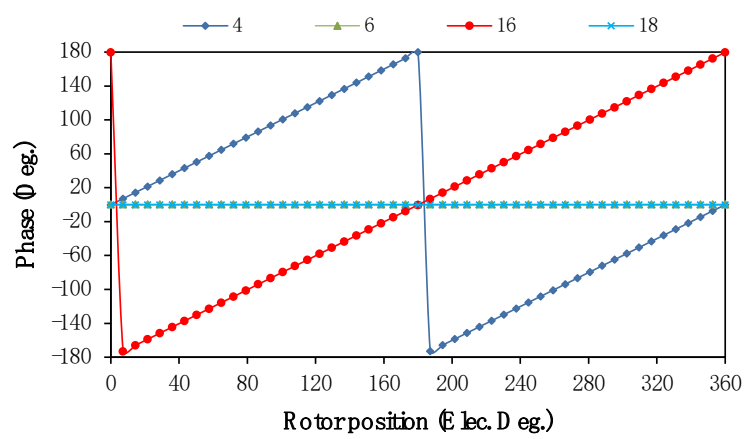

(c)

Fig. 7. Phase of flux-density harmonics with different pole-pair numbers for practical model. (a) Arising from PMs only. (b) Arising from armature currents only, $\delta=0^{\circ}$. (c) Arising from armature currents only, $\delta=90^{\circ}$.

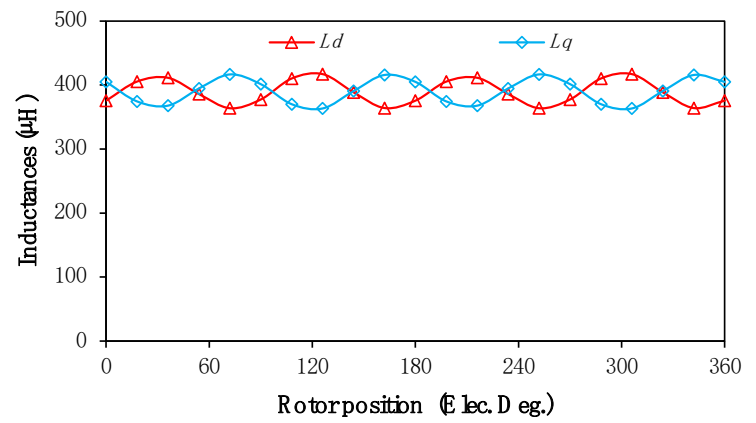

Fig. 8. FEA-predicted $d$ - and $q$-axis inductances waveforms of the $12 \mathrm{~s} / 10 \mathrm{p}$ SFPM machine.

\section{CONClusion}

In this paper, by using a simple permeance-MMF model, air-gap flux-density harmonics produced by PMs and armature currents of SFPM machines are derived. Then, by analysis of EHPs at different current angles $\delta$, the following conclusions are drawn: 
1) SFPM machines can be decomposed to multitudes of EHPs.

2) The phase of each armature flux-density harmonic changes accordingly with the current angle $\delta$, and the torque adjusting principle of each EHP resembles that of surface-mounted PMSMs. When the current angle is equal to $90^{\circ}$, the corresponding armature flux-density harmonics are orthogonal to the PM flux-density harmonics in each EHP, indicating maximal output torque for a fixed armature current amplitude. However, if the current angle is equal to $0^{\circ}$, the corresponding armature flux-density harmonics are aligned or reversely aligned to the PM flux-density harmonics in each EHP, thus resulting in zero output torque.

3) In light of the foregoing analysis, the equality of $d$ - and $q$-axis inductances of SFPM machines can be demonstrated indirectly according to the torque equation of AC PM machines.

4) Finally, FEA has been performed to validate the analytically-predicted results, which shows the pole-pair numbers and phases of air-gap field harmonics predicted by FEA are in good agreement with those by the analytical method. Moreover, the $d$ - and $q$-axis inductances are also calculated to be almost equal by FEA, which is consistent with the previous analytically derived results.

\section{ACKNOWLEDGMENT}

This work was supported by the National Natural Science Foundation of China (NSFC51777190, NSFC51477150), and the Natural Science Foundation of Zhejiang Province (LZ17E070001).

\section{REFERENCES}

[1] M. Cheng, W. Hua, J. Zhang and W. Zhao, "Overview of StatorPermanent Magnet Brushless Machines," in IEEE Transactions on Industrial Electronics, vol. 58, no. 11, pp. 5087-5101, Nov. 2011.

[2] Z. Q. Zhu and J. T. Chen, "Advanced Flux-Switching Permanent Magnet Brushless Machines," in IEEE Transactions on Magnetics, vol. 46, no. 6, pp. 1447-1453, June 2010.

[3] J. T. Chen and Z. Q. Zhu, "Winding Configurations and Optimal Stator and Rotor Pole Combination of Flux-Switching PM Brushless AC Machines," in IEEE Transactions on Energy Conversion, vol. 25, no. 2, pp. 293-302, June 2010.

[4] Y. Du et al., "Comparison of Flux-Switching PM Motors With Different Winding Configurations Using Magnetic Gearing Principle," in IEEE Transactions on Magnetics, vol. 52, no. 5, pp. 1-8, May 2016.

[5] W. Hua, M. Cheng, Z. Q. Zhu and D. Howe, "Analysis and Optimization of Back EMF Waveform of a Flux-Switching Permanent Magnet Motor," in IEEE Transactions on Energy Conversion, vol. 23, no. 3, pp. 727-733, Sept. 2008.

[6] Y. Shi, L. Jian, J. Wei, Z. Shao, W. Li and C. C. Chan, "A New Perspective on the Operating Principle of Flux-Switching PermanentMagnet Machines," in IEEE Transactions on Industrial Electronics, vol. 63, no. 3, pp. 1425-1437, March 2016.

[7] Z. Z. Wu and Z. Q. Zhu, "Analysis of Air-Gap Field Modulation and Magnetic Gearing Effects in Switched Flux Permanent Magnet Machines," in IEEE Transactions on Magnetics, vol. 51, no. 5, pp. 1-12, May 2015.

[8] Z. Q. Zhu, Y. Pang, D. Howe, S. Iwasaki, R. Deodhar and A. Pride, "Analysis of electromagnetic performance of flux-switching permanentmagnet Machines by nonlinear adaptive lumped parameter magnetic circuit model," in IEEE Transactions on Magnetics, vol. 41, no. 11, pp. 4277-4287, Nov. 2005. 